\title{
Partial monosomy $14 q$ involving FOXG1 and NOVA1 in an infant with microcephaly, seizures and severe developmental delay
}

\author{
H. Fryssira ${ }^{1}$, E. Tsoutsou' ${ }^{1}$ S. Psoni ${ }^{1}$, S. Amenta ${ }^{2}$, T. Liehr ${ }^{6}$, E. Anastasakis ${ }^{7}$, Ch Skentou ${ }^{5}$, A. Ntouflia ${ }^{3}$, I. Papoulidis ${ }^{3}$, \\ E. Manolakos ${ }^{3,8^{*}}$ and N. Chaliasos ${ }^{4}$
}

\begin{abstract}
Background: FOXG1 gene mutations have been associated with the congenital variant of Rett syndrome (RTT) since the initial description of two patients in 2008. The on-going accumulation of clinical data suggests that the FOXG1variant of RTT forms a distinguishable phenotype, consisting mainly of postnatal microcephaly, seizures, hypotonia, developmental delay and corpus callosum agenesis.

Case presentation: We report a 6-month-old female infant, born at 38 weeks of gestation after in vitro fertilization, who presented with feeding difficulties, irritability and developmental delay from the first months of life. Microcephaly with bitemporal narrowing, dyspraxia, poor eye contact and strabismus were also noted. At 10 months, the proband exhibited focal seizures and required valproic acid treatment. Array-Comparative Genomic Hybridization revealed a 4. $09 \mathrm{Mb}$ deletion in 14q12 region, encompassing the FOXG1 and NOVA1 genes. The proband presented similar feature with patients with 14q12 deletions except for dysgenesis of corpus callosum. Disruption of the NOVA1 gene which promotes the motor neurons apoptosis has not yet been linked to any human phenotypes and it is uncertain if it affects our patient's phenotype.
\end{abstract}

Conclusions: Since our patient is the first reported case with deletion of both genes (FOXG1-NOVA1), thorough clinical follow up would further delineate the Congenital Rett-Variant phenotypes.

Keywords: FOXG1 syndrome, Rett syndrome, NOVA1, Array-CGH, Postnatal microcephaly, Seizures

\section{Background}

Since 2008, when mutations in the FOXG1 gene were initially described in two patients with Rett-like symptoms, more than 90 patients have been reported to have mutations involving the FOXG1 gene [1-6]. Rett syndrome is typically an X-linked neurodegenerative condition [6] that was initially described by Andreas Rett in 1966. Common clinical features of Rett syndrome include postnatal microcephaly, autism, seizures, breathing abnormalities, growth retardation and gait apraxia $[7,8]$. The majority of patients with typical Rett syndrome carry mutations in the gene encoding Methyl-CpG-binding protein 2 (MECP2) located at Xq28. Variant forms of Rett syndrome have been revised

\footnotetext{
* Correspondence: manolakos@atg-labs.gr

3"Access to Genome" Clinical Laboratory Genetics, Athens Thessaloniki, Greece

${ }^{8}$ Department of Medical Genetics, Binaghi Hospital, University of Cagliari,

Cagliari, Italy

Full list of author information is available at the end of the article
}

in 2010 by Neul et al [7]. He classified them in to three main variant categories: 1 . Preserved speech, 2 . early seizures and, 3. the congenital variant. Mutations in the cyclin-dependent kinase-like 5 (CDKL5) gene located in $\mathrm{Xp} 22$ are found in most cases of early-onset seizure variants, while the congenital variant of the syndrome has recently been found to be associated with heterozygous mutations or deletions in the forkhead box protein G1 (FOXG1) gene, located in the 14q12 chromosomal region $[7,9-11]$. In this study, we report a new case of atypical Rett Syndrome with a 14q12 deletion, $4.09 \mathrm{Mb}$ in size, encompassing only two genes, the FOXG1 and the NOVA1 and we discuss the role of the NOVA1 haploinsufficiency.

\section{Case presentation}

Our patient was a 6-month- old female infant and the only child of non-consanguineous parents. She was born 
by caesarean section at 38 weeks of gestation. Her birth weight was $2.990 \mathrm{gr}\left(25^{\text {th }}-50^{\text {th }}\right.$ centile), her length was $49 \mathrm{~cm}\left(25^{\text {th }}-50^{\text {th }}\right.$ centile $)$ and her head circumference was $33 \mathrm{~cm}$ (10-25th centile).

It should be noted that the embryo was the product of in vitro fertilization (IVF) by intracytoplasmic sperm injection (ICSI) due to the husband's low sperm count. The mother underwent treatment with Follitropin Beta (Puregon), human Chorionic Gonadotropin, hCG (Pregnyl), and Cetrorelix Acetate (Cetrotide).

The patient as a neonate was hypotonic. She was referred for clinical evaluation at the age of 6 months due to irritability and feeding difficulties. The examinations revealed peripheral hypertonia, psychomotor retardation (limited facial expression-no smile, poor eye contact), borderline microcephaly (head circumference of $39 \mathrm{~cm}$, at $3^{\text {rd }}$ centile) (Fig. 1a), periodical stereotypic movements and minor dysmorphic features such as a small forehead with bitemporal narrowing, strabismus, broad base to nose and long philtrum. Her weight was $6.18 \mathrm{~kg}$ (25th centile) and her height was $62 \mathrm{~cm}$ (25th centile).

Due to gastroesophageal reflux she was treated with ranitidine.

Haematological, biochemical, metabolic, thyroid, ammonia and blood gasses were all normal. The ultrasounds of the heart and abdomen were also normal.

At 10 months the proband exhibited focal seizures and required valproic acid treatment. Sleep deprived EEG examination revealed slower focal activity for her age and sleep spindles which are indicative signs of focal cerebral dysfunction. Brain magnetic resonance imaging (MRI) showed no serious findings except for a septum pellucidum cyst and brain asymmetry-the left hemisphere was larger than the right one.

At the age of 12 months, the head circumference was $40.7 \mathrm{~cm}\left(<<3^{\text {rd }}\right.$ centile) (Fig. 1a) while the height and

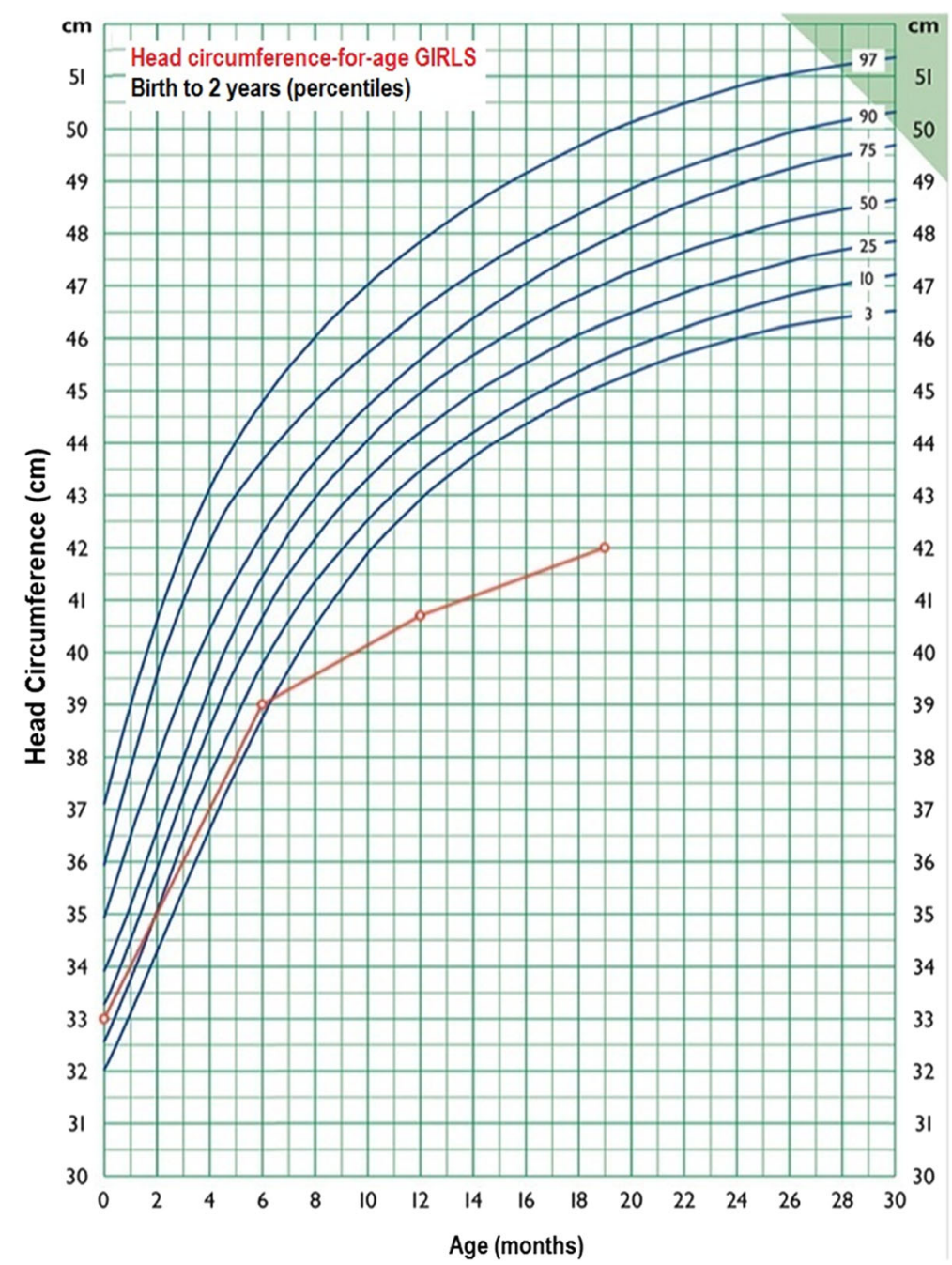

Fig. 1 Growth curve "Head circumference-for-age GIRLS. First Paediatric department, National and Kapodistrian University of Athens. Professor G.Chroussos. The standard curves are used by the Greek National Health System 
weight remained between $10^{\text {th }}$ and $25^{\text {th }}$ centile. Severe neurodevelopmental delay was obvious.

Re-examination at the age of 19- months and 2years, revealed head circumference of $42 \mathrm{~cm}\left(<<3^{\text {rd }}\right.$ centile) (Fig. 1a), height of $75.5 \mathrm{~cm}$ (slightly below the $3^{\text {rd }}$ centile) and weight of $9 \mathrm{Kg}$ (slightly below the $3^{\text {rd }}$ centile). The proband exhibited severe psychomotor retardation as she could neither sit independently nor speak at all.

\section{Chromosome and array-based analysis}

Metaphase chromosomes were obtained from phytohemagglutinin (PHA)-stimulated peripheral blood lymphocytes and high resolution (550-650 bands) thymidine treatment G-banding karyotype analysis was performed, using standard procedures. Twenty metaphase spreads were analysed, and the result was a normal female karyotype (46, XX). The molecular analysis of the $M E C P 2$ gene was normal also.

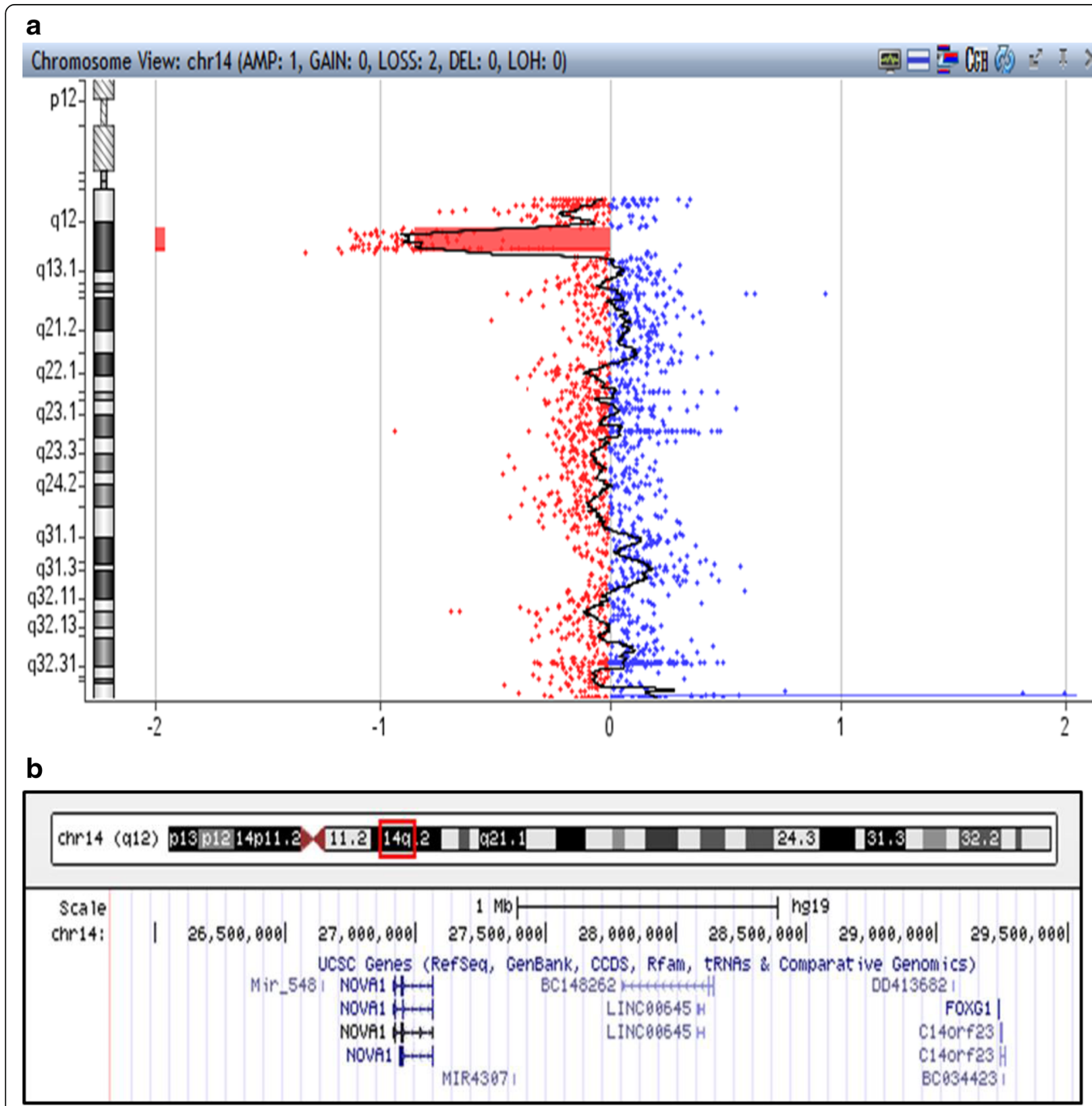

Fig. 2 Array-CGH analysis detected a 4.09 Mb loss of the copy numbers in the spanning region 14q12. b Chromosome 14, region 25,843,560-29,938,629. Represents the 4,095,070 bp deletion described in our case report. The region includes both FOXG1 and NOVA1 genes. Figure adapted from http://genome.ucsc.edu/ Accessed at 18/10/2015 
Further investigation with array-Comparative Genomic Hybridization was performed by hybridizing the sample against a male human reference commercial DNA sample (Promega biotech) using an array-CGH platform that includes 60,000 oligonucleotides distributed across the entire genome (Agilent Technologies). The statistical test used as parameter to estimate the number of copies was ADAM-2 (provided by the DNA analytics software, Agilent Techn.) with a window of $0.5 \mathrm{Mb}, \mathrm{A}=6$. Only those copy number changes that affect at least 5 consecutive probes with identically oriented change were considered as Copy Number Variations (CNV). For the majority of the genome, the average genomic power of resolution of this analysis was 200 kilobases. Array-CGH analysis detected a $4.09 \mathrm{Mb}$ loss in the $14 \mathrm{q} 12$ region (Fig. 2a). The deleted segment was mapped at chr14:25,843,560$29,938,629$ region. The genomic coordinates are listed according to genomic build GRCh37/hg19, and includes FOXG1 and NOVA1 genes (Fig. 2b).

The result of array-CGH was confirmed with FISH. Ten metaphases were analysed from phytohemagglutinin (PHA)-stimulated peripheral blood lymphocytes of the patient with RP11-120I18 in 14q12 and wcp 14 probes. The rearrangement was molecular cytogenetically unbalanced (data not shown), therefore the karyotype is: 46, XX, del[12](q12q12).ish14q12(RP11-120118-). arr[hg19]14q12 $(25,843,560-29,938,629) \times 1$. Blood samples from both parents were examined with FISH in order to exclude any chromosome rearrangement like inversion. Ten metaphases were analysed from each subject with RP11-332 N6 in 14q11.2, RP11-120I18 in 14q12 and wcp 14 probes, and no rearrangement was detected (data not shown).

\section{Discussion}

Recently, the FOXG1 congenital variant of Rett syndrome has been described as a clinically identifiable phenotype, called the "FOXG1 syndrome" [13]. This is an epilepticdyskinetic developmental encephalopathy with features of classic Rett syndrome, but earlier onset from the first months of life. The main phenotype comprises postnatal microcephaly, severe developmental delay and lack of speech, hypotonia, dyskinesia and corpus callosum hypoplasia. Other symptoms include strabismus, feeding difficulties, bruxism and seizures [8, 12-16].

In the present study, a novel FOXG1 and a NOVA1 deletion is described. According to the diagnostic criteria for typical and atypical Rett syndrome [7], our patient possesses only some of the diagnostic criteria for the atypical Rett syndrome. She has slight facial dysmorphism, feeding difficulties, severe psychomotor retardation, postnatal microcephaly, seizures and focal cerebral dysfunction, strabismus and hypertonia. A deletion of 4.09 $\mathrm{Mb}$ on chromosome 14q12 including the FOXG1 and NOVA1 genes was identified by array-CGH technique. The clinical phenotypes vary between the reported cases that have mutations or deletions involving the FOXG1 gene and other genes (Table 1, Fig. 3). Our case differs as only two genes, FOXG1 and NOVA1, are involved. These genes were found to be highly expressed in the human brain throughout ontogeny, and double strand breaks in 14q12 region are implicated in the neurodegenerative disease: ataxia telangiectasia [17].

Different clinical features have also been described in patients with FOXG1 point mutations. The severity or lack of the symptoms among cases could depend

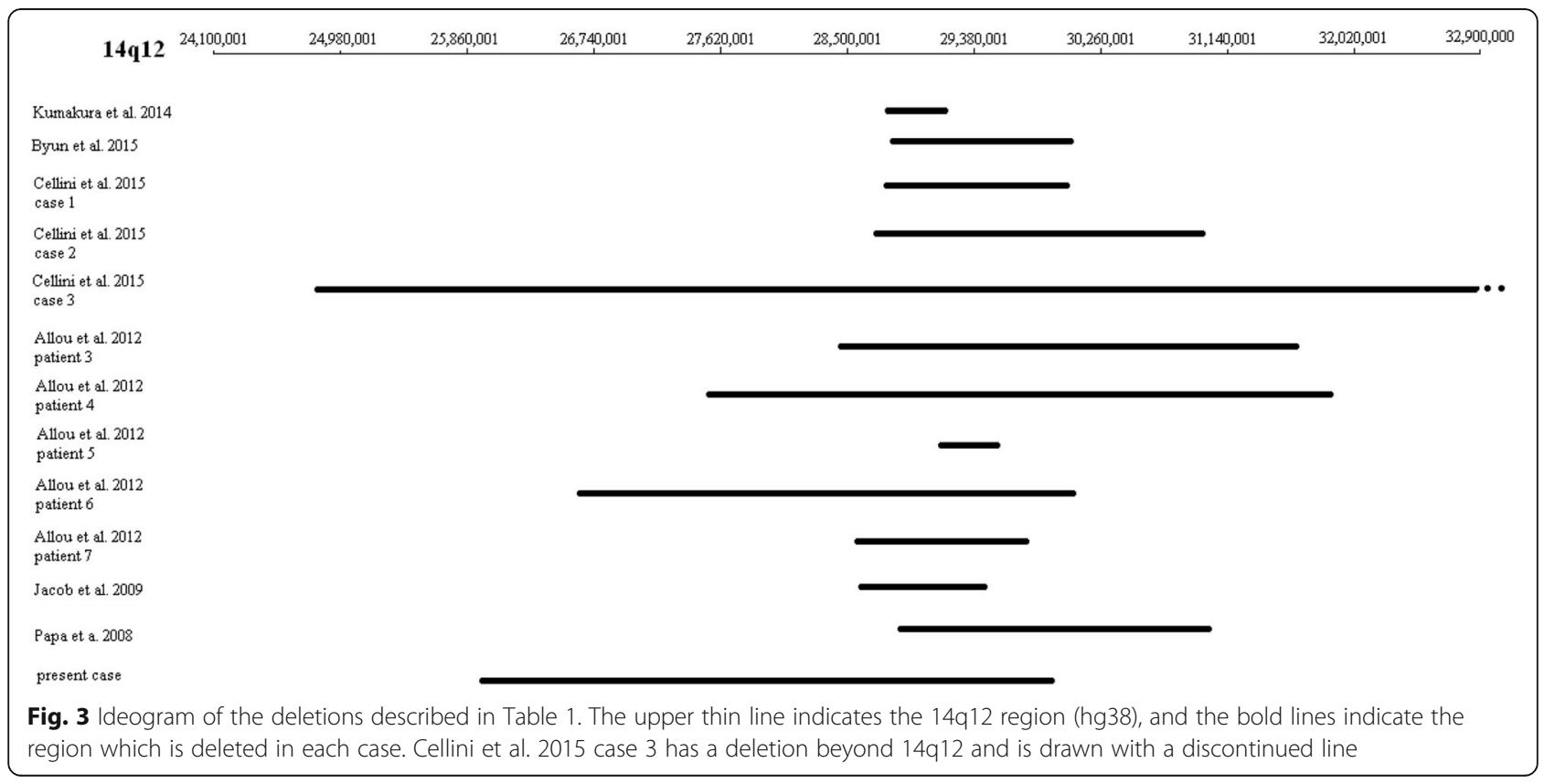




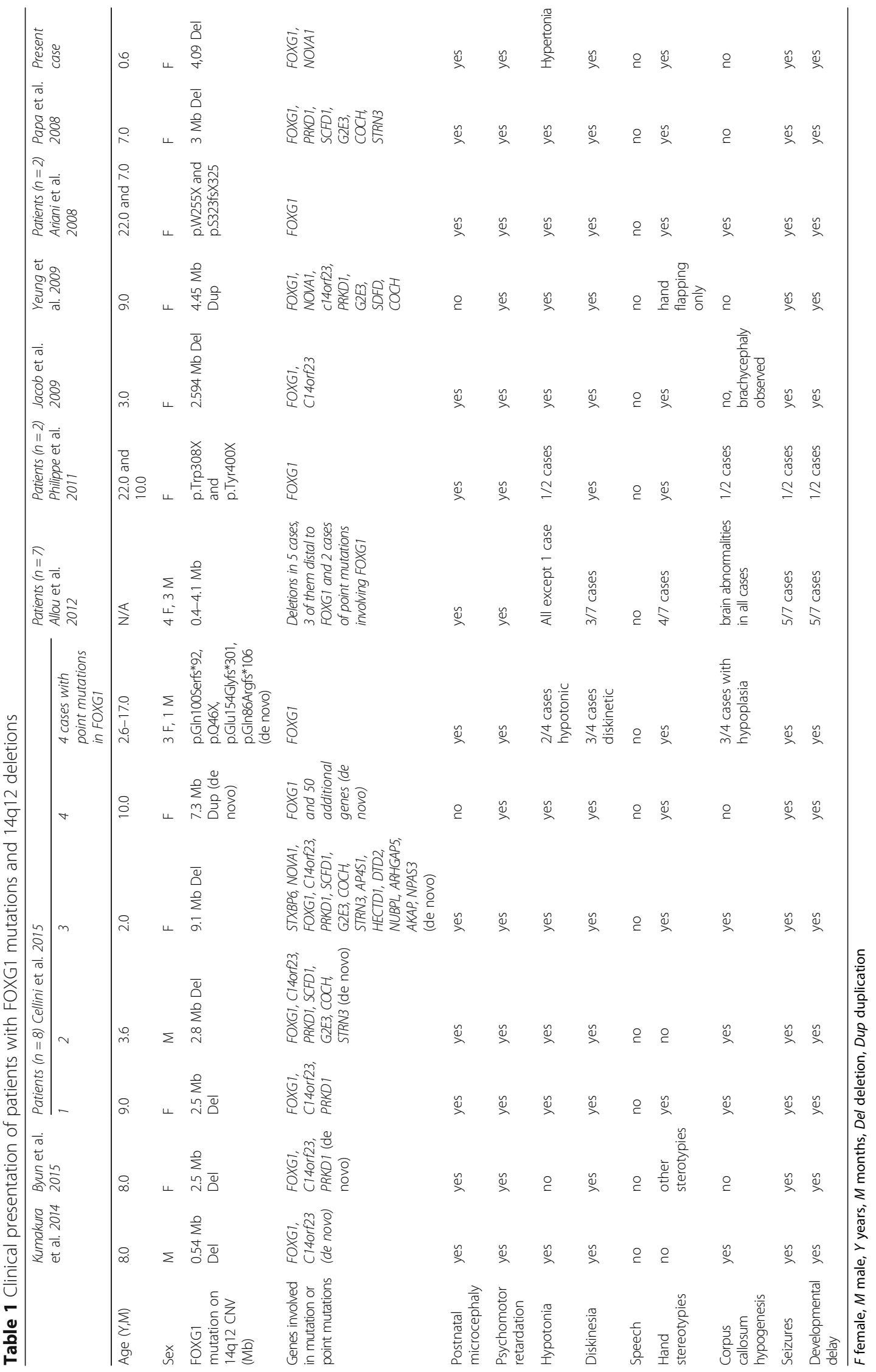


additionally on genetic and/or environmental factors [13]. Jacob F. et al. in 2009 [9] reported a case of a $2.594 \mathrm{Mb}$ deletion involving the FOXG1 and C23orf14 (Table 1). As in our case, patient had a normal corpus callosum but showed all the typical characteristics found in patients with FOXG1 alterations. Table 1 indicates that almost all cases suffer from microcephaly, dyskinesia, lack of speech, seizures and developmental delay. On the other hand, hypotonia and corpus callosum hypoplasia are not apparent in every case. Progressive hypertonia was obvious in our patient and in at least 10 other reported cases with FOXG1 point mutations [8].

Forkhead BOX G1 (FOXG1) gene (OMIM*164874) encodes a developmental transcription factor with repressor activity, important for the development of the ventral telencephalon in the embryonic forebrain and crucial for the regulation of neurogenesis and neurite outgrowth. It is also expressed in neurogenetic regions of the postnatal brain [15]. Postnatal microcephaly is another common feature of FOXG1 syndrome. In cases with a duplication of the FOXG1 gene, microcephaly is not found (Table 1), indicating that the phenotype is dependent on FOXG1 dosage. Furthermore, other reported cases with deletions close but not disturbing the FOXG1 gene have a similar phenotype as patients with "FOXG1 syndrome", suggesting that a position effect causing altered expression of FOXG1 gene may be the cause. The protein Kinase D1 (PRKD1) gene (OMIM*605435), located close to FOXG1 gene has been reported to be implicated in transcription and expression of FOXG1 gene [14].

Neuro-Oncological Ventral Antigen 1 (NOVA1) gene (OMIM*602157) encodes a neuron-specific RNAbinding protein that is inhibited by paraneoplastic antibodies [18]. Recently, Storchel H et al., 2015 [19] found that NOVA1 protein converges on Ago proteins and controls miRNA-induced silencing complex (miRISC), possibly resulting on the regulation of neuronal development and synaptic plasticity. Despite the significant role of the NOVA1 gene, it has not been linked to any human phenotype yet. In the case of our patient with FOXG1 syndrome, we are unable to estimate the impact of the NOVA1 haploinsufficiency. NOVA1 haploinsufficiency may act synergistically with the FOXG1 gene or it may cause no difference in the final clinical outcome. Also, we cannot define whether the IVF by ICSI plays a role in the microdeletion of chromosome $14 \mathrm{q} 12$ region. Further research should investigate if ICSI could be associated with haploinsufficiency as was the case in our patient.

In conclusion, we present a female patient with clinical features compatible with the congenital variant of Rett syndrome.

\section{Conclusion}

Since our patient is the only one with a deletion encompassing only FOXG1 and NOVA1 genes, in the future the thorough clinical follow-up of her neurological status will help for further delineation of the role of these genes.

\section{Abbreviations}

CGH, comparative genomic hybridization; EEG, electroencephalogram; ICSI, intracytoplasmic sperm injection; IVF, in vitro fertilization; MRI, magnetic resonance imaging; PHA, phytohemagglutinin; RTT, Rett syndrome

\section{Acknowledgments}

The authors would like to thank the members of the family of the patient for their collaboration.

\section{Funding}

The whole study was funded by the private company Access to Genome, Clinical Laboratory Genetics, 33A Ethn. Antistaseos str, 55134 Thessaloniki, Greece.

\section{Availability of data and materials}

The datasets during and/or analysed during the current study are available from the corresponding author on reasonable request.

\section{Authors' contributions}

AN and CS wrote the manuscript; HF, ET, SP and SA coordinated the clinical analysis of the patient; EM performed the cytogenetic analysis; IP signed out the molecular cytogenetic results; EM, IP and NC coordinated the study; All authors have read and approved the manuscript.

\section{Competing interests}

The authors declare that they have no competing interests.

\section{Consent for publication}

Written informed consent was obtained from the patient for publication of this case report and any accompanying images. A copy of the written consent is available for review by the Editor-in-Chief of this journal.

\section{Author details}

${ }^{1}$ Medical genetics, School of Medicine, National and Kapodistrian University of Athens, "Aghia Sophia" Children's Hospital, Athens, Greece. "2Mitera"

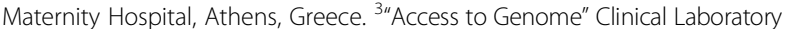
Genetics, Athens Thessaloniki, Greece. ${ }^{4}$ Child Health Department, University

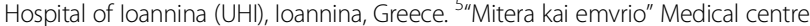
Larisa, Greece. Institute of Human Genetics, Jena University Hospital, Friedrich Schiller University, Jena, Germany. ${ }^{7}$ Hellenic Navy Hospital, Deinokratous 70, Athens 11521, Greece. ${ }^{8}$ Department of Medical Genetics, Binaghi Hospital, University of Cagliari, Cagliari, Italy.

Received: 28 April 2016 Accepted: 25 July 2016

Published online: 02 August 2016

\section{References}

1. Ariani F, Hayek G, Rondinella D, et al. FOXG1 is responsible for the congenital variant of Rett syndrome. Am J Hum Genet. 2008;83:89-93.

2. Takagi M, Sasaki G, Mitsui T, Honda M, Tanaka Y, Hasegawa T. A 2.0 Mb microdeletion in proximal chromosome $14 \mathrm{q} 12$, involving regulatory elements of FOXG1, with the coding region of FOXG1 being unaffected, results in severe developmental delay, microcephaly, and hypoplasia of the corpus callosum. Eur J Med Genet. 2013;56(9):526-8

3. Perche $O$, Haddad G, Menuet A, Callier P, Marcos M, Briault S, Laudier B. Dysregulation of FOXG1 pathway in a 14q12 microdeletion case. Am J Med Genet. 2013;161A(12):3072-7.

4. Ellaway CJ, Ho G, Bettella E, Knapman A, Collins F, Hackett A, McKenzie F, Darmanian A, Peters GB, Fagan K, Christodoulou J. 14q12 microdeletions excluding FOXG1 give rise to a congenital variant Rett syndrome-like phenotype. Eur J Hum Genet. 2013;21(5):522-7.

5. Stenson PD, Mort M, Ball EV, Shaw K, Phillips A, Cooper DN. The Human Gene Mutation Database: building a comprehensive mutation repository for 
clinical and molecular genetics, diagnositic testing and personalized genomic medicine. Hum Genet. 2014;133:1-9.

6. Kumakura A, Takahashi S, Okajima K, Hata D. A haploinsufficiency of FOXG1 identified in a boy with congenital variant of Rett syndrome. Brain Dev. 2014;36(8):725-9

7. Neul JL, Kaufmann WE, Glaze DG, et al. Rett Syndrome: revised diagnostic criteria and nomenclature. Ann Neurol. 2010;68:944-50.

8. Byun CK, Lee JS, Lim BC, Kim KJ, Hwang YS and Chae J. FOXG1 Mutation is a Low-Incidence Genetic Cause in Atypical Rett Syndrome. Child Neurology Open. 2015;8:1-5

9. Jacob F, Ramaswamy V, Andersen J, Bolduc F. Atypical Rett syndrome with selective FOXG1 deletion detected by comparative genomic hybridization: case report and review of literature. Eur J Hum Genet. 2009;17:1577-81.

10. Papa FT, Mencarelli MA, Caselli R, et al. A 3 Mb Deletion in 14q12 Causes Severe Mental Retardation, Mild Facial Dysmorphisms and Rett-like Features. Am J Med Genet. 2008;146:1994-8.

11. Pantaleón FG, Juvier RT. Molecular basis of Rett syndrome: A current look. Rev Chil Pediatr. 2015;86:142-51.

12. Allou $L$, Lambert $L$, Amsallem D, Bieth E, Edery P, Destree $A$, et al. 14q12 and severe Rett-like phenotypes: new clinical insights and physical mapping of FOXG1-regulatory elements. Eur J Hum Genet. 2012;20:1216-23.

13. Kortüm F, Das S, Flindt M, Morris-Rosendahl DJ, Stefanova I, Goldstein A, et al. The core FOXG1 syndrome phenotype consists of postnatal microcephaly, severe mental retardation, absent language, dyskinesia, and corpus callosum hypogenesis. J Med Genet. 2011;48:396-406.

14. Pratt DW, Warner JV, Williams MG. Genotyping FOXG1 mutations in patients with clinical evidence of the FOXG1 syndrome. Mol Syndromol. 2013;3(6): 284-7.

15. Florian C, Bahi-Buisson N, Bienvenu T. FOXG1-related disorders: from clinical description to molecular genetics. Mol Syndromol. 2012;2:153-63.

16. Cellini E, Vignoli A, Pisano T, et al. The hyperkinetic movement disorder of FOXG1-related epileptic-dyskinetic encephalopathy. Dev Med Child Neurol. 2016:58:93-7.

17. Iourov IY, Vorsanova SG, Liehr T, Kolotii AD, Yurov YB. Increased chromosome instability dramatically disrupts neural genome integrity and mediates cerebellar degeneration in the ataxia-telangiectasia brain. Hum Mol Genet. 2009;18:2656-69.

18. Buckanovich RJ, Yang YY, Darnell RB. The onconeural antigen Nova-1 is a neuron-specific RNA-binding protein, the activity of which is inhibited by paraneoplastic antibodies. J Neurosci. 1996;16:1114-22.

19. Störchel PH, Thümmler J, Siegel G, Aksoy-Aksel A, Zampa F, Sumer S, et al. A large-scale functional screen identifies Nova1 and Ncoa3 as regulators of neuronal miRNA function. EMBO J. 2015;34:2237-54.

\section{Submit your next manuscript to BioMed Central and we will help you at every step:}

- We accept pre-submission inquiries

- Our selector tool helps you to find the most relevant journal

- We provide round the clock customer support

- Convenient online submission

- Thorough peer review

- Inclusion in PubMed and all major indexing services

- Maximum visibility for your research

Submit your manuscript at www.biomedcentral.com/submit

CBiomed Central 